03.1

\title{
Изучение структуры течения в перспективном вихревом топочном устройстве
}

\author{
() С.В. Алексеенко, И.С. Ануфриев, Е.Ю. Шадрин ॠ, О.В. Шарыпов \\ Институт теплофизики им. С.С. Кутателадзе СО РАН, Новосибирск, Россия \\ "E-mail: evgen_zavita@mail.ru
}

Поступило в Редакцию 16 июля 2019г.

В окончательной редакции 16 июля 2019 r.

Принято к публикации 6 августа 2019г.

\begin{abstract}
Экспериментально исследована внутренняя аэродинамика изотермической лабораторной модели усовершенствованной четырехвихревой топки пылеугольного котла. С использованием метода цифровой трассерной визуализации получены распределения компонент осредненной скорости потока воздуха и проекции линий тока в ряде сечений модели при различных режимах работы топки, определяемых соотношением скоростей потоков, подаваемых через основные и вторичные сопла. Определены условия формирования устойчивой структуры течения с четырьмя симметричными сопряженными вихрями во всем объеме топки, а также диапазон режимных параметров, приводящих к нерегулярной в пространстве вихревой структуре.
\end{abstract}

Ключевые слова: четырехвихревая топка, изотермическая модель, внутренняя аэродинамика, цифровая трассерная визуализация.

DOI: 10.21883/PJTF.2019.22.48646.17984

В настоящее время, как и в обозримой перспективе, уголь является одним из основных видов топлива для производства энергии. Оборудование современных ТЭС рассчитано на угольное топливо высокого качества, запасы которого ограничены. Этим обусловлена необходимость вовлечения в топливно-энергетический баланс низкосортного твердого топлива (непроектные угли, биомасса, различные отходы) [1]. Сжигание такого топлива на существующем оборудовании приводит к технологическим проблемам и накладывает жесткие требования на системы топливоподготовки, золо- и шлакоулавливания, очистки уходящих газов и т.П. Поэтому актуальной задачей является научное обоснование разработки топочных устройств для энергоэффективного и экологически безопасного сжигания непроектного твердого топлива.

Применение вихревых технологий сжигания топлива позволяет повысить показатели процесса горения топлива. Закрутка потока обеспечивает интенсификацию перемешивания и межфазного тепломассообмена в двухфазном потоке, устойчивое воспламенение низкореакционного топлива, высокую полноту сгорания за счет многократной циркуляции топливных частиц в камере горения, уменьшение производства вредных продуктов сгорания благодаря более однородному распределению температуры, устранение шлакования теплообменных поверхностей в результате создания определенной структуры потока [2-6]. Ключевым этапом научного обоснования разработки таких технологий является физическое моделирование аэродинамики на лабораторных моделях перспективных вихревых камер сгорания.

Настоящая работа посвящена экспериментальному исследованию внутренней аэродинамики модели усовер- шенствованного топочного устройства с четырехвихревой структурой потока. Подобные по конструкции топки действующих котлов ТЭС обладают существенными недостатками (связанными в первую очередь с интенсивным шлакованием), устранение которых может быть обеспечено созданием приемлемой структуры потока в модернизированной вихревой камере.

Модель выполнена в масштабе 1:25 (внутренний размер $290 \times 880 \times 730 \mathrm{~mm})$ из прозрачного оргстекла для проведения оптических исследований (рис. 1). На боковых стенках в три яруса установлены по две диагонально направленные насадки (соответствующие горелочным амбразурам) под углом $6^{\circ}$ (размер $\left.28 \times 50 \mathrm{~mm}\right)$ так, что их оси ориентированы горизонтально и направлены к центральной вертикальной оси топки. Фронтальные сопла (соответствующие подаче вторичного воздуха) также установлены в три яруса на передней и задней стенках (на той же высоте, что и боковые сопла), и исходящие из них потоки направлены к боковым стенкам под углом 20․ Размер фронтальных сопел составляет $23 \times 66 \mathrm{~mm}$. Размеры сопел выбраны из соображения подобия лабораторной модели полноразмерным топкам. Средний ярус сопел располагается на полувысоте модели. Основным отличием от существующих топок, аэродинамика которых исследована в работе [7], является симметричное расположение фронтальных горелок для обеспечения симметрии и устойчивости закрученного потока в широком диапазоне режимных параметров.

Исследования выполнены на экспериментальном стенде, основными элементами которого являются автоматизированная регулируемая система подачи сжатого воздуха; устройство засева потока частицами-трассерами, необходимыми для проведения измерений; модель усо- 


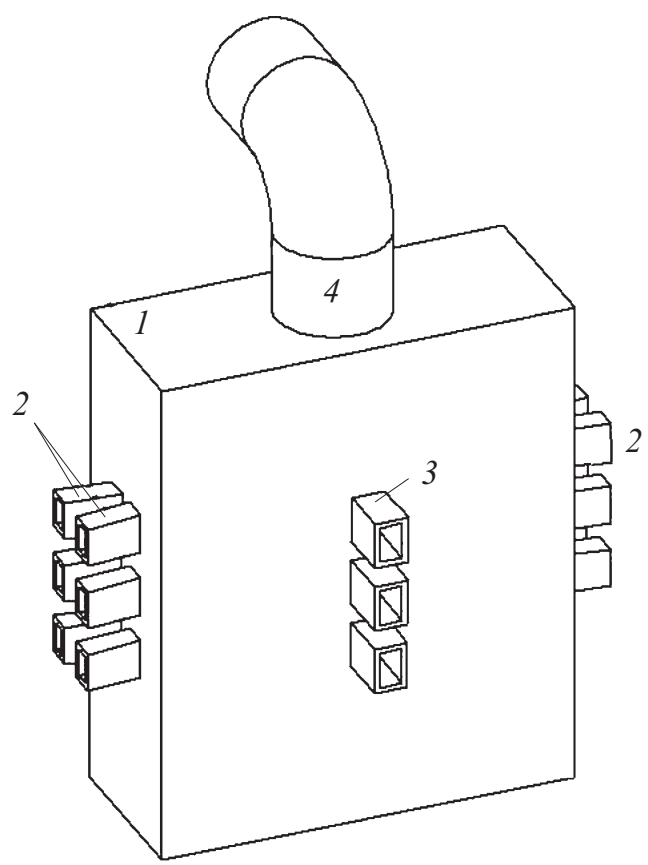

Рис. 1. Схема модели четырехвихревой топки. 1 - камера сгорания, 2 - боковые сопла, 3 - фронтальные сопла, 4 газоход.

вершенствованной топки; измерительная система; вентиляция. Методика проведения эксперимента аналогична описанной в работе [8]. Для проведения бесконтактных оптических измерений применялась PIV-система „Полис“, состоящая из цифровой CCD-камеры ImperX B4820 (16 Mpx), двойного Nd:YAG-лазера QuantelEVG (энергия импульса до $145 \mathrm{~mJ}$ ), объектива Nikon (фокусное расстояние $50 \mathrm{~mm}$ ), синхронизующего процессора, компьютера со специальным программным обеспечением ActualFlow. Для перемещения измерительной системы использовалось координатно-перемещающее устройство с точностью позиционирования $0.1 \mathrm{~mm}$.

Измерения проведены в ряде горизонтальных сечений, проходящих через центры ярусов горелок. В каждом сечении получена серия из 1000 пар изображений (задержка между кадрами в паре $100 \mu \mathrm{s})$. По результатам цифровой обработки изображений с использованием итерационного кросскорреляционного алгоритма получена информация о распределении двух компонент осредненной скорости в заданных сечениях. Измерения выполнены при различных скоростях потоков (от 1 до $5 \mathrm{~m} / \mathrm{s}$ на выходе из сопел), определяющих режим работы котла. Измерения проведены в одной половине сечения модели, что позволило повысить пространственное разрешение (шаг сетки $5 \mathrm{~mm}$ ) при размере кадра $290 \times 340 \mathrm{~mm}$. Характерное значение числа Рейнольдса, рассчитанное по длине вихревой камеры при данных скоростях, $\operatorname{Re}>10^{5}$, т.е. результаты получены в диапазоне Re, в котором обеспечивается автомодельность структуры потока. Таким образом, результаты характеризуют особенности аэродинамики в полномасштабных топках.
На рис. 2 представлено векторное поле скорости, полученное в горизонтальной плоскости, проходящей на полувысоте топки, для режима, при котором скорости на выходе из боковых и фронтальных сопел составляют 5 и $2 \mathrm{~m} / \mathrm{s}$ соответственно (отношение скоростей $\beta=2.5$ ). Верхняя часть рис. 2 построена как зеркальное отражение нижней части, в которой проведены измерения. Потоки, выходящие из боковых сопел, доходя до центра

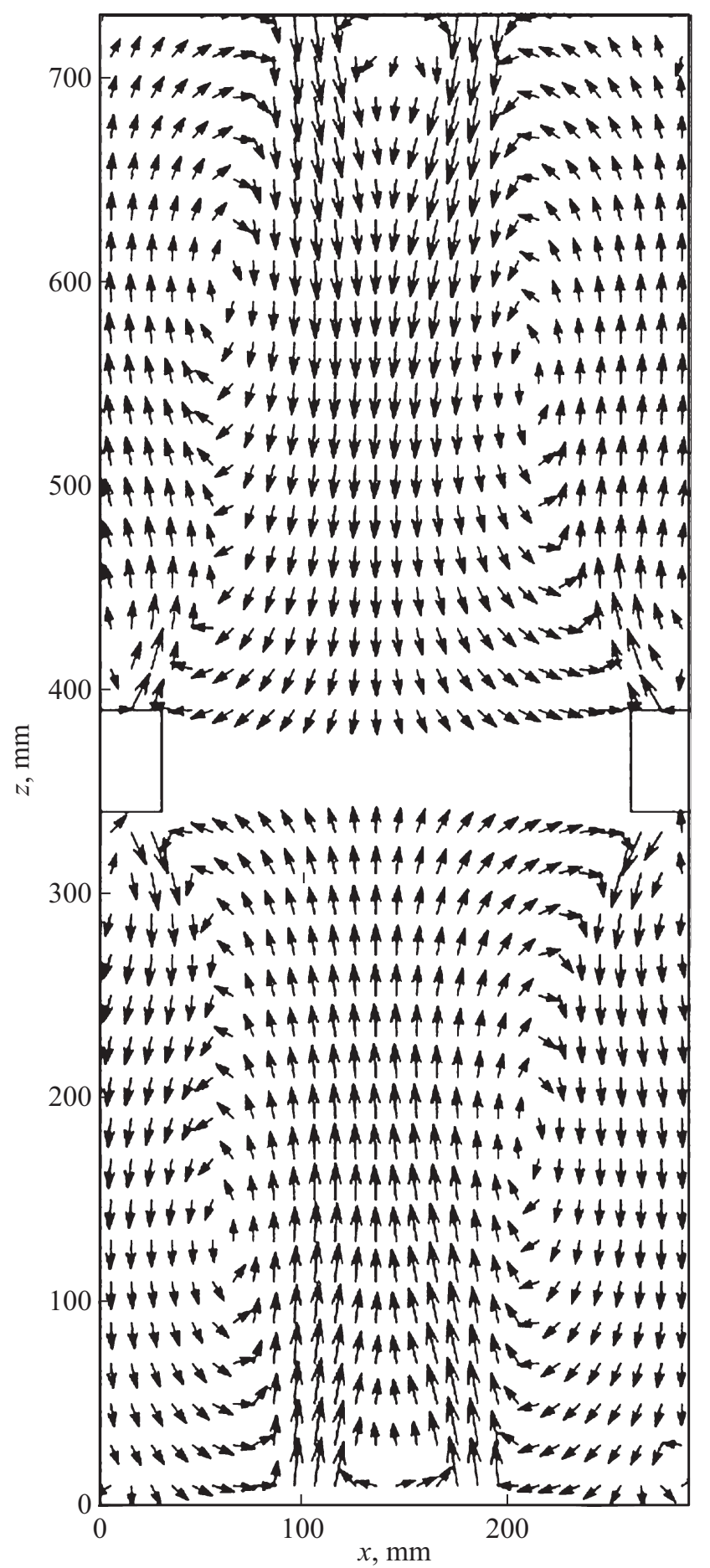

Рис. 2. Векторное поле осредненной скорости в горизонтальном сечении на полувысоте топки. 

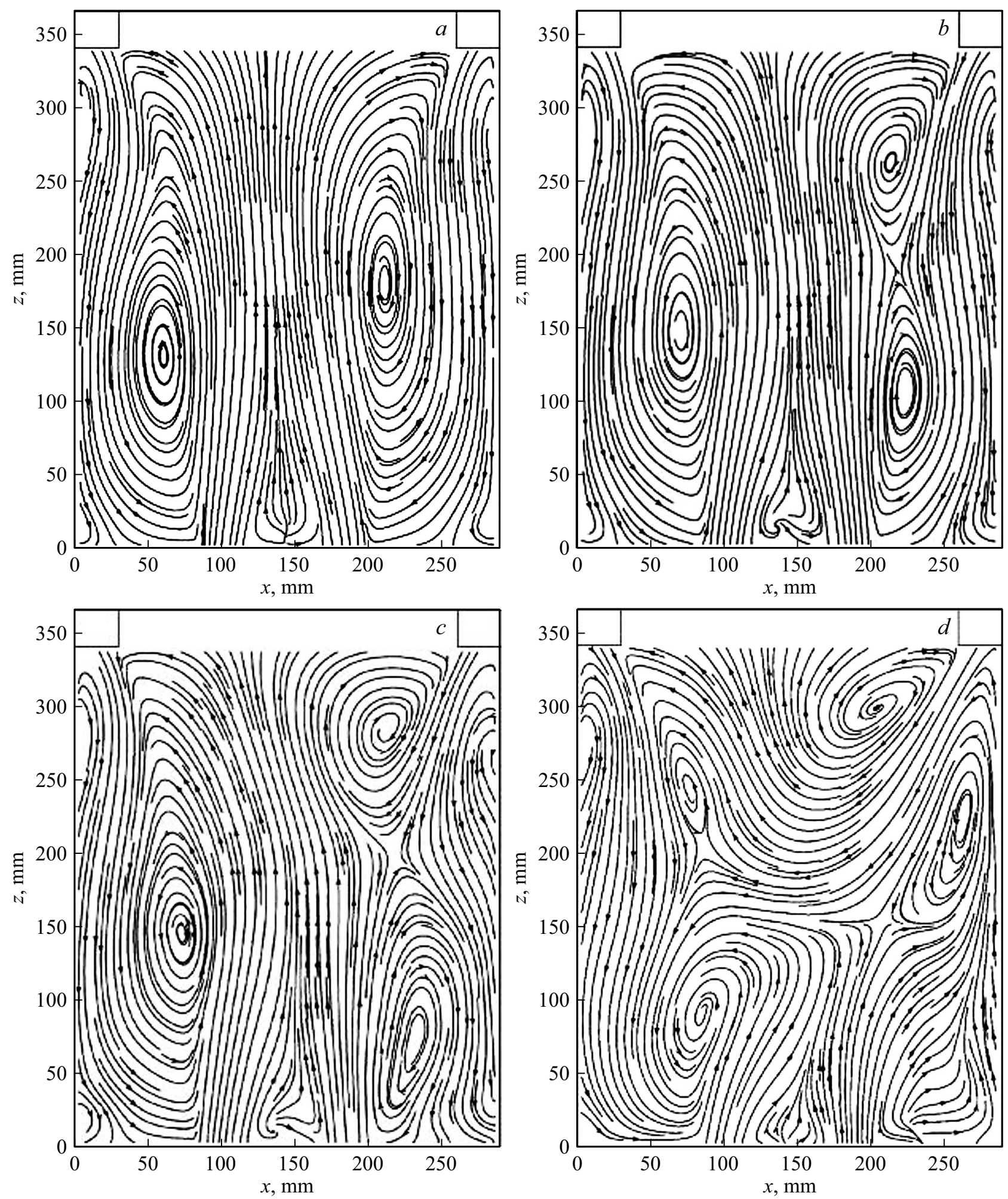

Рис. 3. Линии тока в горизонтальном сечении на полувысоте топки для характерных режимов с $\beta=2.5,1.5,1.0,0.5$ при различных скоростях потоков через боковые и фронтальные сопла: $a-5$ и $2 \mathrm{~m} / \mathrm{s} ; b-3$ и $2 \mathrm{~m} / \mathrm{s} ; c-2$ и $2 \mathrm{~m} / \mathrm{s} ; d-2$ и $4 \mathrm{~m} / \mathrm{s}$.

топки, взаимодействуют с потоками, подаваемыми через фронтальные сопла, разворачиваются и замыкаются, образуя интенсивно закрученное течение с четырьмя сопряженными вихрями (рис. 2). Такая картина течения характерна для всех трех исследуемых сечений на разной высоте топки.

На рис. 3 изображены осредненные проекции линий тока для половины площади аналогичного сечения, 
построенные по результатам PIV-измерений. Представлены характерные результаты при четырех различных отношениях скоростей через боковые и фронтальные сопла: 5 и $2 \mathrm{~m} / \mathrm{s}(\beta=2.5$, рис. $3, a) ; 3$ и $2 \mathrm{~m} / \mathrm{s}(\beta=1.5$, рис. $3, b) ; 2$ и $2 \mathrm{~m} / \mathrm{s}(\beta=1.0$, pис. $3, c) ; 2$ и $4 \mathrm{~m} / \mathrm{s}(\beta=0.5$, pис. $3, d)$. Диапазон значений параметра $\beta=2.5-1.0$ соответствует режимам работы разрабатываемого котла. Анализ результатов показывает, что при $\beta \geqslant 2$ реализуются режимы течения с четырьмя симметричными сопряженными вихрями (в том числе при $\beta=2.0,2.5,4.0$, 5.0 для различных комбинаций скоростей от 1 до $5 \mathrm{~m} / \mathrm{s}$ ). В режимах с $\beta \leqslant 1$ структура течения полностью утрачивает симметрию, в различных сечениях наблюдается разное количество вихрей (в том числе при $\beta=1.0$, $2 / 3,0.5$ для скоростей от 2 до $4 \mathrm{~m} / \mathrm{s}$ ). В промежуточном диапазоне $2>\beta>1$ в ряде сечений наблюдается шесть вихрей с нарушением симметрии (в том числе при $\beta=5 / 3,1.5,4 / 3$ для скоростей от 2 до $5 \mathrm{~m} / \mathrm{s})$. С практической точки зрения хаотизация структуры течения при понижении значения параметра $\beta$ ниже характерного критического уровня $(\beta \approx 2)$ означает, что в этих режимах невозможно организовать эффективное омывание стенок, необходимое для предотвращения шлакования теплообменных поверхностей. Таким образом, режимы при $\beta<2$ неблагоприятны для работы котла.

Проведенные исследования показали, что для изученной усовершенствованной модели вихревой топки соотношение скоростей потоков на выходе из боковых и фронтальных сопел $(\beta)$ является параметром, определяющим качественные характеристики структуры потока в вихревой камере. Результаты, полученные для различных комбинаций скоростей входящих потоков, позволяют выделить три диапазона значений данного параметра, которым соответствуют режимы течения c регулярной (четыре симметричных вихря, $\beta \geqslant 2$ ), переходной $(2>\beta>1)$ и нерегулярной (хаотической) вихревой структурой $(\beta \leqslant 1)$. Проведение исследований при $\operatorname{Re}>10^{5}$ позволяет прогнозировать применимость результатов к полномасштабному котельному оборудованию. Задавая $\beta \geqslant 2$, можно обеспечивать благоприятный для работы котла режим с интенсивно закрученным течением с четырьмя симметричными сопряженными вихревыми структурами во всем объеме топки. Наряду с этим полученные данные необходимы для верификации физико-математической модели процессов в реальных условиях с целью дальнейшего проведения трехмерного моделирования аэродинамики и процессов переноса в полноразмерной топке.

Все результаты получены авторами статьи.

\section{Финансирование работы}

Работа выполнена при финансовой поддержке Российского научного фонда (проект № 19-19-00443).

\section{Конфликт интересов}

Авторы заявляют, что у них нет конфликта интересов.

\section{Список литературы}

[1] Тугов А.Н., Рябов Г.А., Штегман А.В., Рыжий И.А., Литун Д.С. // Теплоэнергетика. 2016. № 7. С. 3-11.

[2] Редько А.А., Редько И.А., Редько А.Ф. // Проблемы региональной энергетики. 2017. № 3. С. 33-44.

[3] Саломатов В.В. // Изв. Томск. политехн. ун-та. 2014. № 4. C. 25-37.

[4] Любов В.К., Ивуть А.Е. // Вестн. Череповец. гос. ун-та. 2016. № 5(74). С. 16-20.

[5] Красинский Д.В. // Теплофизика и аэромеханика. 2016. № 5. C. 815-818.

[6] Казимиров С.А., Багрянщев В.И., Бровченко С.А., Темлянцев М.B. // Наукоемкие технологии разработки и использования минеральных ресурсов. 2015. № 2. С. 342-345.

[7] Анубриев И.С., Шарыпов О.В., Дектерев А.А., Шадрин Е.Ю., Папулов А.П. // Теплофизика и аэромеханика. 2017. № 6. C. 873-879.

[8] Ануфриев И.С., Стрижак П.А., Чернецкий М.Ю., Шадрин Е.Ю., Шарыпов О.В. // Письма в ЖТФ. 2015. Т. 41. B. 15 . C. 25-32. 